Wilfrid Laurier University

Scholars Commons @ Laurier

Lyle S. Hallman Social Work Faculty

Publications

Lyle S. Hallman Faculty of Social Work

2009

\title{
The Experiences of Minority Immigrant Families Receiving Child Welfare Services: Seeking to Understand How to Reduce Risk and Increase Protective Factors
}

\author{
Sarah Maiter \\ Wilfrid Laurier University, smaiter@wlu.ca \\ Carol A. Stalker \\ Wilfrid Laurier University, cstalker@wlu.ca \\ Ramona Alaggia \\ University of Toronto
}

Follow this and additional works at: https://scholars.wlu.ca/scwk_faculty

Part of the Social Work Commons

\section{Recommended Citation}

Maiter, Sarah; Stalker, Carol A.; and Alaggia, Ramona, "The Experiences of Minority Immigrant Families Receiving Child Welfare Services: Seeking to Understand How to Reduce Risk and Increase Protective Factors" (2009). Lyle S. Hallman Social Work Faculty Publications. 2.

https://scholars.wlu.ca/scwk_faculty/2

This Article is brought to you for free and open access by the Lyle S. Hallman Faculty of Social Work at Scholars Commons@ Laurier. It has been accepted for inclusion in Lyle S. Hallman Social Work Faculty Publications by an authorized administrator of Scholars Commons @ Laurier. For more information, please contact scholarscommons@wlu.ca. 


\title{
The Experiences of Minority Immigrant Families Receiving Child Welfare Services: Seeking to Understand How to Reduce Risk and Increase Protective Factors
}

\author{
Sarah Maiter, Carol A. Stalker, \& Ramona Alaggia
}

\begin{abstract}
Wide recognition that families in the child welfare system experience multiple stressors has resulted in the development of a range of prevention and intervention strategies at individual, family, and policy levels. ${ }^{1}$ This article reports on a research study with minority immigrant families. The aim was to understand stressors they perceived as contributing to child welfare interventions, and services they found helpful or unhelpful. Using the conservation of resource (COR) theory, the findings highlight the erosion of resources that increases their vulnerability. Themes that emerged were: loneliness, betrayal, hopelessness, and financial and language struggles. Application of the COR theory combined with contextual insights from participant perspectives can guide policy and practice to focus on resource gain and prevent resource attrition.
\end{abstract}

D esearch has suggested that minority children experience more negative consequences as a result of abuse than maltreated children from the dominant culture (Cohen, Deblinger, Mannarino, \& de Arellano, 2001). Furthermore, if families come in contact with the child welfare system, minority and poor children are often treated differently than their White counterparts as they move through the system (Courtney et al., 1996; Hogan \& Siu, 1988). Members of minority groups are often also immigrants from countries with different customs and practices, and research on the experience of immigrants confirms that the process of migration is associated with considerable stress. In view of research that associates multiple stressors with child maltreatment, it is important for child welfare workers to have an in-depth understanding of the experience of families who are both immigrants and members of minority groups.

Child maltreatment includes neglect; physical, emotional, and sexual abuse; and exposure to parental abuse. It is an issue that touches people from all parts of society. Maiter, Alaggia, and Trocmé (2004) reminded us that in all cultures, parental discipline methods range from useful and appropriate to abusive and

${ }^{1}$ The terms "child welfare services" and "child protection services" are often used interchangeably in the literature. For the sake of consistency, we have used the term "child welfare services" throughout this paper. unacceptable. Many of the challenges of immigration, including language barriers, difficulty securing employment, and cultural differences (Segal \& Mayadas, 2005; Pine \& Drachman, 2005) will affect all newcomers in a country. However, as noted earlier, the literature suggests being a person of minority status can have an effect on one's experience in the child welfare system. Despite the possible negative interaction between being a person of color and having contact with child protection agencies, literature in this area is lacking. Behl, Crouch, May, Valente, and Conyngham (2001) reviewed child welfare literature from 1977 to 1998 and found only a small increase during those years in focus on the relationship between client ethnicity and intervention in response to allegations of child maltreatment. Other criticisms of the literature in this area include observations that research often fails to look at both the effect that culture has on factors that lead to maltreatment (Korbin, 2002) and effective intervention options (Cohen et al., 2001). Similarly, the interaction between the immigration experience and the experience of being a member of a minority group also lacks investigation. In light of these findings, it is essential that practitioners gain a better understanding of how the process of migration and being a minority affects the development of risk and protective factors that may influence people's experience with the child welfare system. This article reports 
on findings from a qualitative study that explored the experiences of 20 South Asian immigrants to Canada who had child welfare involvement. The term "South Asian" is now commonly used to refer to people whose ancestry originates from the Indian subcontinent and surrounding regions such as Bangladesh, Bhutan, India, Maldives, Pakistan, and Sri Lanka. South Asian also refers to individuals from Africa, Mauritius, Fiji, the Caribbean, Guyana, Great Britain, and European countries who trace their origins to the Indian subcontinent.

\section{Literature Review}

\section{The Migration Experience}

The experience of migration affects people in many different ways, and several researchers have tried to better understand this process. Segal and Mayadas (2005, p. 565) suggested a framework for the immigrant experience that considers impacts of the premigration stage (including living conditions, status, and experience in and reasons for leaving their country of origin), the migration process (including the transition to the new country, resources available to aid in the transition process, and the host country's political and social openness to newcomers), and postmigration (including the adjustment to the new culture). Pine and Drachman (2005, p. 545) listed a number of factors that influence each stage of migration including age, family composition, urban/rural background, race, education, culture, socioeconomic background, occupation, belief, and social support. In their model, country of origin, premigration, departure, transit, country of resettlement, return to home country, and return to resettlement country are aspects that need to be taken into account when working with immigrant families. Both models provide practitioners with a framework from which to begin the process of understanding their diverse clients. It is important to keep in mind that gathering knowledge that is only culturally specific can lead to mistakes in the kinds of services that are provided for clients (Maiter, 2004). Service providers thus need to develop a flexible understanding of how migration affects families. The concept of acculturation helps shed more light on the migration process.

\section{Acculturative Stress}

It can be assumed that in the early stages of migration, many migrants face both language and economic barriers. Even migrants with a strong grasp of the dominant culture's language and a stable financial situation will need to negotiate the nuances of living in a new country. Conger et al. (2002) tested the usefulness of a family stress model to understand the relationship between economic difficulties and child adjustment in African American homes with two caregivers. They found economic difficulties affect family functioning and child adjustment primarily because of the significant emotional struggles that are associated with financial difficulties for most caregivers.

Similarly, language plays a key role in migrant adjustment to a new place. Segal and Mayadas (2005) identified poor English language ability as the most significant barrier to integration in the United States. Rhee, Chang, and Youn (2003) explored Korean American pastors' ideas about child abuse and reported that immigrants from Korea named language difficulties as the most stressful challenge they face. Low proficiency in English frequently leads to poor employment opportunities, decreased income, nega- tive health effects, and poverty (Capps, Passel, Periz-Lopez, \& Fix, 2003). Thus, low proficiency in English could put people at risk of experiencing acculturative stress. Likewise, Greenland and Brown (2005) found increased acculturative stress was related to greater levels of intergroup anxiety. Intergroup anxiety has been defined as anxiety individuals experience when meeting or anticipating contact with an "out-group" member; it can be caused by being in the minority in terms of numbers, as well as by initial expectations and stereotypes. It is possible that language ability and intergroup anxiety are connected; people with minimal language capabilities are more likely to experience negative reactions from members of the dominant culture when intergroup anxiety is high.

\section{For immigrant families, the well-known pathways to family conflict and child maltreatment are further exacerbated by language struggles.}

In a study on child maltreatment and social isolation, Coohey (1996) looked at parents who either neglected their children, physically abused their children, or both neglected and physically abused their children. She found that all three types of parents had less emotional support than their nonabusive counterparts. In other research looking at maltreatment in Spain and Colombia, parents who abused their children were often more socially isolated and had less positive feelings toward their communities than nonabusing parents (Gracia \& Musitu, 2003). Korbin (2003) noted the long-standing belief in the connection between prevention of child abuse and providing more social support for families. Newcomers in a culture often face depression and feelings of being alone in the first years they spend in a new place (Segal \& Mayadas, 2005), and depressed feelings have been associated with acculturative stress (Zheng \& Berry, 1991). These feelings are likely to be magnified for people who come from cultures in which extended family assisted in sharing the task of child rearing. In other words, newcomers would be expected to struggle in their new homes when they receive no respite for their parenting duties (Deepak, 2005; Maiter, 2003; Roer-Strier, 2001). For parents struggling with feelings of isolation and depressed mood, the challenge of negotiating the expectations of two cultures is made worse and can often seem overwhelming. Their children may be embracing behaviors and expectations of the new culture, which may or may not have been acceptable in their country of origin, thus adding to the difficulties that parents face.

\section{Adaptive Adults}

Roer-Strier and Rosenthal (2001) introduced the idea of an "adaptive adult" to understand socialization in different cultural contexts. They suggested child rearing and socialization are "functional and future-oriented" (p. 216). Culture is considered 
the main influence on parental ideas about what constitutes an adaptive adult. Helping children to gain the skills needed to be adaptive adults is considered the goal of child development and socialization. It is likely that parents refer to traits considered adaptive in the past, as well as those considered adaptive for the future, when making decisions about how to reach their parenting goals (Roer-Strier, 2001). Changes in ideas about adaptive adults can take place at all four ecological levels (micro-, meso-, exo-, and macro- system) as described by Bronfenbrenner (1989). Conflict would be expected when there is a clash between parental and dominant cultural beliefs about the traits that are needed for a person to be an adaptive adult (Roer-Strier \& Rosenthal, 2001). It is likely that child-rearing strategies could be affected by parental perceptions as to whether or not their children are acquiring the skills needed to be successful as they grow out of childhood.

\section{Multiple Stressors}

Clearly it is impossible to depict one single picture of what it means to be an immigrant or refugee (Segal \& Mayadas, 2005); however, the literature summarized earlier suggests although the experience differs from person to person, the transition of moving to a new country is very stressful for most people who immigrate. Individual factors, familial characteristics, particular traditions, and the nature of the interaction between the values of the home culture and those of the host culture will influence people at each stage of the migration process (Pine \& Drachman, 2005). For people who are not proficient in the dominant culture's language, a number of additional risk factors arise, including financial difficulties resulting from an inability to find employment (or desirable employment) and increased stress related to poor working conditions (Rhee et al., 2003). If one of the central goals of parenting is to raise adaptive adults, and culture is one of the most influential components of parental perceptions of what makes an adult adaptive, immigrants can be expected to struggle with trying to find a balance between the values of the two cultures with which they interact.

The critical role multiple stressors play in contributing to child maltreatment is now widely acknowledged (Belskey, 1993), with most theories of child maltreatment identifying that there is no one pathway to child maltreatment; rather, maltreatment occurs when stressors outweigh supports, and risks are greater than protective factors. Considerable research has been conducted to further our understanding of the contributions of these stressors to the etiology of child maltreatment, and services have been developed to address the problems. These studies, however, have neglected to examine the unique context of immigrant minority families.

\section{The Conservation of Resources Theory of Stress}

The conservation of resources (COR) theory of stress has proved useful both in increasing understanding of the specific conditions that lead to stress in a variety of contexts and in identifying means of reducing stress (Hobfoll, 1998; 1988). The central tenet of the theory is that people strive to obtain, retain, protect, and foster that which they value. Hobfoll (1998) called what people value "resources"-and resources are defined as "the objects, conditions, personal characteristics, and energies that are themselves valued for survival, directly or indirectly, or serve as a means of achieving these ends" (p. 54). Following from the central tenet, Hobfoll stated: stress occurs in circumstances that represent a threat of loss or actual loss of the resources required to sustain the individualnested-in family-nested-in-social organization. Furthermore, because people will invest what they value to gain further, stress is predicted to occur when individuals do not receive reasonable gain following resource investment, this itself being an instance of loss.

Hence, stress occurs when (1) resources are threatened with loss, (2) resources are actually lost, or (3) there is failure to adequately gain resources following significant resource investment (Hobfoll, 1998, p. 55). Resources, in addition to money and material objects, include social support systems, employment, economic status, knowledge, sense of mastery, self-esteem, hope, and optimism.

The original COR theory has been expanded to include recognition that "environments and people interact differently based on individuals' social status, gender, ethnicity, and personal attributes" (Hobfoll, 1998, p. 89). Hobfoll pointed out that although most Western societies claim to value citizen rights and equality under the law, the reality is that limitations are placed on certain members of society based on stereotypes, stigma, or other forms of bias. This has the effect of limiting what they are able to achieve in spite of the amount of resources they may possess or to which they have access. Furthermore, for some individuals, a positive bending of the rules occurs "either to lower obstacles in the environment or artificially over-evaluate resources (i.e., to make resources worth more than they are, not just to think they are so)" (p. 109). This theory has considerable potential to increase our understanding of the experiences of immigrant minority groups.

The study reported here, by listening to the voices of members of one immigrant minority group who have been child welfare clients, examined the particular stressors in the lives of these families and considered the degree to which the COR theory of stress was useful in making sense of the findings. It also used the COR theory to guide consideration of how changes might be made to reduce the stress in this group.

\section{Method}

\section{Research Design}

An inductive, qualitative research methodology, using the long interview method (LIM) developed by McCracken (1988), was adopted to explore the lives of immigrant families involved with the child welfare system. A qualitative approach was chosen because of its capacity to provide a holistic understanding of the lives of participants (Fetterman, 1989; Strauss \& Corbin, 1998) that the "controlled" and "reductive" procedures of quantitative research might miss (Sherman \& Reid, 1994). Although the study gathered data on both the context of client lives and interventions they received from the child welfare system, this article focuses on the context of the participant lives. Their descriptions of the situations in which they found themselves illustrate the many sources of acculturative stress with which they were trying to cope. These rich data can contribute to service provider understanding of the struggles faced by this particular client group. Increased understanding of this context by service providers is likely to lead to more effective helping and better outcomes for those families 
who come in contact with child welfare organizations (Hartman, 1994; Lincoln \& Guba, 1985; Pieper, 1989; Sherman \& Reid, 1994). In essence, we wanted to consider the "life world" of the client because this life world is so different from the practitioner's life world, such that, without assistance, it can be difficult for practitioners to enter and understand (Ruckdeschel, Earnshaw, \& Firrek, 1994). The overall aim of the study was to understand stressors in the lives of minority immigrant families they perceived as contributing to child welfare interventions, and services they found helpful or unhelpful. As noted this article reports on the former question.

\section{Selection of Participants and Data Collection}

Participants were initially recruited through a child welfare agency in a large metropolitan Canadian city that has a high percentage of immigrants. Potential participants (all those who self-identified as South Asian) were confidentially identified by the research director of the agency through the open case list (cases that were open for ongoing service). Letters with information about the study and a request to contact the researcher were mailed to all potential participants and followed up with a telephone call. No exclusion criteria were employed. Participants were offered the choice of having the interview conducted in their native language or in English. Most chose to be interviewed in English. When participants agreed, a trained doctoral student of social work conducted the interview, which was tape-recorded and later transcribed. Additional participants were recruited through ethno-specific counselling agencies and through word of mouth. Participants were given an honorarium of 50 dollars for their participation. The procedures for the study received institutional approval by the university ethics committee as well as by the ethics committee of the child welfare agency involved in the study.

\section{Interview Guide}

An interview guide, based on extensive review of the literature and input from key experts at ethno-specific counselling agencies, was developed and pilot-tested. Areas for exploration included family history, migration history, settlement history, impact of cultural and racial diversity on family members, availability of social supports, loss of social supports, emotional and psychological resources of parent(s), financial resources, parent-child interactions, problems of children, approaches to parenting, factors resulting in child welfare intervention, participant view of child protection involvement in the family, type of services offered, whether services were useful, and whether other services would have been more useful.

\section{Data Analysis}

At the initial coding stage, two trained research assistants and the principal investigator read four transcripts and developed a tentative coding scheme based on the interview questions. Data were analyzed using this coding scheme, with new codes added as new concepts emerged. The coding scheme reached saturation at the reading of the ninth interview and did not change after this point. A second level of coding was developed once the initial coding was completed. This second-level coding searched for deeper meaning and overall themes in the data. The transcribed interviews were imported into NVIVO (QSR NUD*IST Vivo) - a computer software program for organizing non-numerical (qualitative) data.

A key issue in qualitative research is to ensure the trustworthi- ness of the data (Lincoln, 1995; Lincoln \& Guba, 1985), which was done in several ways. The researchers are connected to this research through many years of clinical practice and research in this field, and thus bring perspective and caution to the study. This prolonged engagement guided decisions throughout the research process. Persistent observation occurred through the in-depth interview process. Finally, all emerging themes are supported by quotes and descriptions, to address confirmability and dependability.

A further consideration is the number of cases considered to be sufficient to draw conclusions. McCracken (1988) found categorical saturation on certain topics can be reached after six to eight cases. In this study we analyzed the interview data of 20 participants after which we were reasonably confident no more new information was coming forward on the questions we were pursuing.

\section{Findings}

\section{Participants}

Twenty people -12 women and 8 men-participated in this study. Ten of the parents in the study were in the age range of 30-39; four, 40-49; three, 20-29; and three, 50-59. The mean number of years parents in this sample had been in Canada was 12 with a range of 2-31. Interestingly, three of the parents had been in Canada for more than 30 years, perhaps suggesting the consequences of migration can last a long time. Most participants spoke more than one language, a South Asian language as well as English. Although all the participants noted that they spoke English, many were not fluent. More than half of the participants had a college or university degree. Educational levels ranged from high school to a postsecondary professional degree. Only $22 \%$ of the participants were employed full time, whereas the rest were employed part time or were unemployed. The income of the participants reflected their employment status, with only $27 \%$ having an income over $\$ 40,000$. Average income was $\$ 30,000$, and $40 \%$ of the sample had an income below $\$ 19,000$. Most participants in the study were married; $30 \%$ were lone parents who were either single, separated, divorced, or widowed. On average, most participants had two children with a range of one to four. Most of the households were made up of the nuclear family, although three participants had either a parent or a parent-in-law residing with them.

Six of the participants in the study noted extreme conflict between the spouses as well as with their children as the reason for involvement with the child welfare system. These conflicts included parent-teen issues related to discipline, and intergenerational conflict related to differences between the culture in which the parents were raised and the dominant culture, sometimes resulting in physical abuse of the teen. Some of the conflict was the result of extreme risk-taking behavior of the adolescent that the parents were unable to manage. Four of the families identified mental health issues of either the mother or father as the reason for child welfare involvement; four identified neglect (lack of supervision, inappropriate feeding of baby); three noted exposure to domestic violence; and three noted sexual abuse (one extrafamilial). Several participants expressed they were unaware of the reason for child welfare service intervention, noting they had reached out to community agencies for help that then resulted in the child welfare system becoming involved. This would seem to be a significant issue if participants are unclear about the reason 
for the involvement of the child welfare system and may indicate a greater need for cultural sensitivity in explaining the role of child welfare services to immigrant families.

The large majority of the sample indicated they came to Canada expecting a better life for themselves and their children. Some came to escape war and civil unrest, others to escape poverty and over population. A small number came to join family members who were already here. Mariam, in her 20s, with three children, noted:

We came here for a better life, to have a better future for our children because there is good education here, everybody knows. So they can have a good future, that's the reason.

Essop, in his 40 s, the father of three, said:

When I came to Canada, I was very optimistic that I would get a better job than what I was doing back home, and that my children and my family would be more secure, more stable, and have a better life than what I was leaving behind.

\section{Major Themes}

The data provided rich insights into the lives of immigrant families who had come into contact with the child welfare system. Much of the interview transcripts for all participants confirmed many of the struggles already noted in the literature review section of this article. Like Conger et al. (2002), our data also revealed that caregivers facing extreme financial difficulties experience significant emotional struggles that then impact child rearing. Low proficiency in English has also been identified as one of the most stressful challenges faced by some immigrant groups in relation to child abuse (Rhee et al., 2003), and it has been identified as leading to poor employment opportunities, decreased income, negative health effects, and poverty (Pine \& Drachman, 2005). These effects can increase stress and conflict among family members, as noted by our participants, and can create anxiety in interactions with the dominant group (Greenland \& Brown, 2005).

We organized our findings in the following major themes found in the transcripts: loneliness, financial struggles, language struggles, struggles to provide for the family, and sense of betrayal and hopelessness. These themes were remarkably strong in the transcripts and provide valuable insights into the significant difficulties experienced by this set of immigrants. The themes are noted in the following sections, with quotes to support them, and are discussed thereafter.

\section{Loneliness}

Participants spoke of a great sense of loneliness that also included feelings of isolation and a general sense of not having the supports that were available to them in their home country. Many talked about not having anyone to call on for help if they needed it. The inability to depend on members of the extended family was frequently noted, as was the fast pace of life in the new country. For others, the lack of a sense of belonging was very painful.

Yasmin, in her 30s, the mother of three, said:

Life is dramatically changed because everyone here is very busy and don't have time to spare for you ... but back in Bangladesh we have a lot of friends, relatives, parents. We are parents. We are children. We are nieces. We are in-laws.
Nalini, the mother of two, in her 30s, commented:

In Canada, they don't have the community support. I've seen, you know, in my country you can go to your next-door neighbor. The support you have there, we don't have that here.

Hamid, in his 30s, from Pakistan, noted a similar sentiment:

The lifestyle we have back home, it's not kind of like what we have here. All the families are centered here; all the families are busy here. Nobody has time for someone else. Life is very fast and life is very busy.

Yasmin's comments capture the immense sense of isolation felt by the family:

We landed in Montreal. We stayed for 3 years, and I was very downtrodden. I could say I would never experience, in my life, the bad times that I experienced at that time. Even in Bangladesh I did not have such a bad time. It was really a bad time for my family, my children. We were like fish out of water.

Some participants noted that as they stayed longer, they did feel more settled and made friends, but for some the sense of loneliness continued. Insecurity because of financial difficulties and unstable work tended to enhance the sense of isolation.

\section{Financial Struggles}

Participants spoke about the significant financial strain they were under because of being unemployed or underemployed along with their struggles to find work. Many of the participants took steps to upgrade their education in the hope of finding better jobs. Considerable concerns were evident around current and future financial security for the family, while disappointment about not finding work they were qualified for was also present. In the following quote, Jameela, in her 30s, the mother of three, from Bangladesh, who has been in Canada for 4 years, voiced her concern about the hardship on her husband because of the work that he had to do and her own sense of wanting to help the family:

I think just earning what my husband earns, that's not enough. I want to help him. He goes to work in a factory, and it is a hard job. When he comes back, I feel bad about that. I don't feel good. I can't even help him, and that bothers me a lot. I want to at least work part time or full time. If I can work, if I can help my husband, then I will.

Participants talked about how limited income can create tensions between parents and older children, and how this inability to provide is related to the disparity between the cost of living and the income they are able to obtain. Jameela noted:

She [daughter] is going to the formal, and she is excited to rent a limo. She said, "Mom, I need to rent the limo, and there are three friends that are going to be in the limo." The limo is very expensive, and sometimes they don't understand you can't pay for the limo. She wants her hairstyle, and she wants her nails done, just 20 bucks. But when I'm here [in this country], they think I can afford everything. 
Even social assistance did not solve all of the problems, although one participant held out hope:

\begin{abstract}
The money the welfare people gave us is not enough for surviving. For four people, the maximum they provide is 12 hundred dollars, and you can imagine if you have to pay a thousand dollars for rent, how are you going to survive? How are you going to manage your basic needs when you have kids? And the kids are growing up fast, and they need clothes after 6 months, or you can say after a year they've grown out of their clothing. And we don't have money to shop. You go and look around and come back. So we just sit at home and keep thinking that maybe we're going to be a millionaire and then we'll have fun-I'm just joking! It was very disappointing at that time, but now I think, I'm hoping that my husband, he's a very good driver, and he passed two tests, and I hope, and people have said, that he could earn money driving a taxi or even doing deliveries. I just need to help him to improve his English.
\end{abstract}

As many of the participants were aware, difficulty speaking English contributed to the problems of finding employment and consequently also to the financial difficulties.

\section{Language struggles}

Responses from participants highlighted their struggles to become fluent in English. Many attended English as a second language (ESL) classes in the community to help them either find work or advance in their field. However, many also noted the dilemma of wanting to study in hopes of securing a better job but being constrained by the need to work to support the family. Shirin went on to say, "I am working as a volunteer with some people, and I just need to take some courses in the English language so that I can speak well."

Jameela, mother of three, in her 30 s, also commented on a similar note:

For me and my husband, we need a good job. That, we have to find ourselves. No one is going to help with that. And I have to upgrade my education to find a good job. I have to do, maybe, two, three years here. I also have to do that myself; no one is going to help me with that.

\section{Struggles to Provide for the Family}

Aside from the financial and language struggles that participants spoke about, the interviews provided clear evidence of an overall struggle to provide for their families that is salient to note here. These struggles included working long hours and doing shift work; underemployment or accepting work of lesser status; the stress resulting from inappropriate or inadequate work; attempts to balance work and spending time to learn English; experiences of discrimination when looking for work; and struggles to find child care. Jaiwanti, in her 40 s, mother of one, spoke about the extreme hardship related to long work hours:

I was working Saturday, and Sunday, and 12-hour shifts, too. There was nothing much to do but work 7 days in a row. I worked as a sewing machine operator 5 days, and in the evening I worked in the bakery. I was working 12-hour shifts, and at that time I was paid 5 dollars an hour. My husband also worked driving a taxi.
Jameela spoke about the hardship on her husband of doing work of lesser status in Canada than in the home country:

First of all, he was angry with work here. His work in Bangladesh was office work with other people, but when he came here, he had to work in the factory. So the work before was different from his factory work. It is very hard here for him. He has to be a laborer and do physical labor.

Madhuri, in her 30s, talked about how the abrupt change in the status of her work, combined with long working hours, contributed to much stress:

My husband got a job when he landed here. I landed in August. He joined me in November. He got a job in, say, 5 to 6 days. But that was just an entry-level job, but, at the same time, we had some income coming in. And we bought this condo, and I started my career as a telemarketer, which was itself a great stress. I was earning a lot of money in [home country]. I was heading a whole department, and now I was reduced to a mere telemarketer. You can imagine how stressful that was.

A number of participants felt compelled to support their families rather than attend school. This is captured in the statement by Jaiwanti, mother of one, as she speaks about her husband:

He is an educated person, but he chose to drive a taxi. I tried to tell him, "We are living with somebody, we have support for you to go to school seven days in a row and then to have a nice office job," but, he chooses. He just wanted to support his family. He is still driving a taxi.

Family struggles to find adequate and affordable child care are captured in the comments made by Priti, in her 30s, mother of one:

The lady who looked after him, I pay her 40 dollars per day. What does this mean? This is a lot of money; 200 dollars per week. She then asks me for another 50 dollars per week, but I cannot afford that, and she is not giving me any tax slips either, because she is getting money from welfare. She didn't provide any food for him. I make his food, and I give his diapers as well.

\section{Sense of Betrayal and Hopelessness}

A number of participants in this sample expressed a profound sense of betrayal about the way their lives were turning out in Canada. They had migrated with considerable hope for a better life for themselves and their children. Many had left particularly difficult situations such as political unrest, religious intolerance, lack of opportunity, and overcrowding, while some had left to be closer to family. All expected to become settled in Canada and to gain from the opportunities they saw immigration to Canada could provide. But for many there was an overwhelming sense of betrayal and hopelessness about their experiences as reflected in the quote below. Cassim, in his 40 s, father of four, stated:

I did my 4 years master's degree, and my 6 years another master's degree. I got my visa as a computer system programmer. I proudly got a visa, I proudly came over here, and now I'm 
getting social assistance. My children are growing up on social assistance. Me, I'm an educated person, but I'm living on social assistance. Me, my education, my everything is gone.

The sense of betrayal and hopelessness results in participants questioning their decision to move and reflecting on whether they should return to their home country. Madhuri, noted:

I am really trying to make a decision, you know. What should I do? Should I look for another job, or should I go back to India? I am really, really frustrated at this point in time. Where is the end?

\section{Discussion}

Themes that emerged-loneliness, financial struggles, language struggles, struggles to provide for the family, and sense of betrayal and hopelessness-supported by the rich quotes of the participants provide considerable insight into the struggles of the participants in this study. All the participants in this study discussed the extreme hardships they were experiencing in meeting the needs of their families or in obtaining the resources to care for themselves personally. They identified these struggles as being so overwhelming that, in their view, they contributed to situations that prompted child protection intervention. Clearly, not all immigrants will have such extreme struggles or overwhelming sense of loss. However, some immigrants, as noted by the participants in this study, do experience stressors that can be extremely devastating. The sense of loneliness and isolation noted by the participants has been previously identified as resulting in child abuse and neglect (Coohey, 1996; Gracia \& Musitu, 2003), whereas the importance of community and formal and informal social supports for families both for prevention and intervention are also well-known (Korbin, 2003; Manji, Maiter, \& Palmer, 2005).

The struggles that many families who come into contact with child welfare services in relation to poverty and finances are further exacerbated for the immigrant families in this sample because of low English proficiency, which then impacts their ability to secure employment. These stressors are, however, additive because foreign credentials and experience are not recognized by the host country. Thus a clear path to ending poverty is not so easily available to immigrants. For immigrant families, the well-known pathways to family conflict and child maltreatment are further exacerbated by language struggles. Added to these struggles, families are also concerned with raising adaptive adults, as discussed in the literature review earlier, and with negotiating the transitions they need to make in parenting in the new country. Not clearly identified in the literature, but discussed by our participants, are their feelings of betrayal and hopelessness, and a questioning of whether their decision to migrate was the correct one. Inevitably, family members can experience depression and other mental health problems (Segal \& Mayadas, 2005), adding to the risk of maltreatment. The struggle to create a better life for themselves and their families that now seems to be unattainable can be particularly draining on family emotional resources. Yet families want to make the adjustment to their new country and make the migration process a success. These feelings can be tapped into to increase the protective factors in these families.

In examining our data and the themes found in these data, what became evident to us was that although there were several stressors we could specifically discuss that child protection and other social service and health care workers could target, it was the overall spiral of resource loss and the lack (or seeming lack) of resource gain that many families were struggling with. While we continue to value the contextual information found in our data, we want to introduce the conservation of resources (COR) theory (Hobfoll, 1988), as we feel that it is a more overarching approach that can be used to develop, promote, and provide services for immigrant families who are experiencing conflicts resulting in child welfare interventions. Practitioners can use this theoretical approach supported by the contextual information found in our study to develop individualized approaches for working with this population.

\section{A number of participants expressed a profound sense of betrayal about the way their lives were turning out [in a new country].}

\section{Application of the Conservation of Resources Theory of Stress}

Applying the COR theory of stress, it can be seen that migration inevitably means experiencing the loss of many important resources including one's home, familiar objects, social support system, and employment. In addition, migration frequently results in a decline in economic status, which for some immigrants is temporary but for many is long-standing. Sense of mastery is threatened when the new culture's customs and mores are unknown or unfamiliar. Low proficiency in the dominant language, leading to difficulty communicating, further threatens the sense of competence and mastery. Self-esteem may also be challenged when employment is difficult to secure right away or when the only employment available is of lower status and lower compensation than that previously held or expected.

The COR theory focuses our attention on another form of loss that migrants may experience, namely, the loss felt when the investment of money, hard work, and hope in the move to a new country does not lead to an expected gain in resources. This may be connected to perceptions of having failed as an individual or family, or of having been misled by governmental agencies in promises made about opportunities in the host country. These perceptions are also likely to affect the sense of mastery and selfesteem.

The expansion of the COR theory to include recognition that environments and people react differently based on gender, ethnicity, and other markers of social status is supported by the reports of participants in this study who have found that discrimination and prejudice interfere with their ability to secure employment corresponding to their credentials and knowledge, adding to the stress they experience. 


\section{Implications for Practice}

The implications of the findings from the current study, together with the COR theory of stress, can guide policy and interventions for child welfare agencies and other organizations that work with immigrant populations and wish to contribute to prevention of these problems. The first implication is that efforts must be made to limit as much as possible the resource loss that immigrants experience. Upon arrival, newcomers should be linked with others who share their culture and language and who are able to provide support. Such linkages would reduce the experience of loneliness and isolation. Second, since one's home and family space is a key resource both practically and symbolically, good quality and affordable housing needs to be readily available. Immigrants should also be provided with accessible information about the new culture and its norms as soon as possible after arriving. Such information will facilitate the development of a sense of mastery and a sense of belonging. The COR theory of stress may be useful in targeting families who are experiencing greater losses and/or have fewer resources.

Attention to supporting gains in key resources is crucial. These key resources appear to be language ability and access to appropriate employment. Clearly, making classes in ESL immediately available and accessible to all immigrants is essential. The more quickly newcomers are helped to improve their language skills, the more access they will have to jobs and services. A further barrier that even newcomers with adequate language skills face needs to be addressed, namely, the difficulty they face obtaining employment commensurate with their prior education and training. Greater efforts must be exerted to discourage professional and occupational groups from discriminating and disadvantaging individuals with foreign training and experience.

Changes in these two areas could be the catalyst for the development of "gain cycles" (Hobfoll, 1998). When minority immigrants are able to communicate adequately with members of the dominant culture and obtain work that matches their training and ability, they can more readily embark on gain cycles that will find them adding one resource to another resource and to yet another resource. The cumulative gain in resources and the cumulative decrease in threat of loss of resources will contribute to a sense of mastery, good self-esteem, and increased social support. This will lead to a significant decrease in the risk factors that contribute to contact with child welfare organizations.

At the level of front-line work in child welfare organizations, workers who are more aware and sensitive to the enormous stressors with which many immigrants grapple will be more helpful and effective with these families. Child welfare professionals need to look for and identify the many resources that these families possess and help the family find ways to improve the fit between their resources and the demands being made by the environment. They should inquire of family members (and be genuinely interested in) their experience of migration, and seek to understand what aspects of that process are most stressful for the particular family at that particular point in time. Is the concern about the child or children arising from the accumulation of stress that the family has been experiencing? Can the agency assist the family to build on its current resources or reduce the threat of losing further resources? Can the worker help them to increase the social support they experience, for example, by connecting them to community centers that provide support to parents in culturally compatible ways?

In cases involving parent-child conflict, opportunities to talk with other parents who have experienced similar struggles coming to terms with the effect of the new culture on their children's values and attitudes are likely to be helpful. In cases involving mental health concerns, providing information that the stress involved in migration can lead to mental health problems may be helpful in normalizing the experience; similarly, education about Western attitudes toward mental illness and the treatment available may allay some fears. In many cases, assistance to obtain needed financial support may reduce concerns about neglect.

Clearly, agencies that advocate within their communities for more accessible ESL classes and more supports to immigrants seeking employment are likely to reduce the number of newcomer family referrals. The COR theory suggests that child maltreatment in minority immigrant families can be reduced by efforts focused in a wide variety of ways to prevent the spiral of resource loss, and to increase opportunities for resource gain.

\section{References}

Behl, L. E., Crouch, J. L., May, P. F., Valente, A. L., \& Conyngham, H. A. (2001). Ethnicity in child maltreatment research: A content analysis. Child Maltreatment, 6(2), 143-147.

Belskey, J. (1993). Etiology of child maltreatment: A developmental-ecological analysis. Psychological Bulletin, 114(3), 413-434.

Bronfenbrenner, U. (1989). Ecological systems theory. Annals of Child Development, 6, 187-249.

Capps, R., Passel, J. S., Periz-Lopez, D., \& Fix, M. (2003). The new neighbors: A user's guide to data on immigrants in U.S. communities. Washington, DC: The Urban Institute.

Cohen, J. A., Deblinger, E., Mannarino, A. P., \& de Arellano, M. A. (2001). The importance of culture in treating abused and neglected children: An empirical review. Child Maltreatment, 6(2), 148-157.

Conger, R. D., Wallace, L. E., Sum, Y., Simons, R. L., McLoyd, V. C., \& Brody, G. H. (2002). Economic pressure in African American families: A replication and extension of the family stress model. Developmental Psychology, 38(2), 179-193.

Coohey, C. (1996). Child maltreatment: Testing the social isolation hypothesis. Child Abuse and Neglect, 20(3), 241-254.

Courtney, M. E., Barth, R. P., Berrick, J. D., Brooks, D., Needel, B., \& Park, L. (1996). Race and child welfare services: Past research and future directions. Child Welfare, 75, 99-137.

Deepak, A. C. (2005). Parenting and the process of migration: Possibilities within South Asian families. Child Welfare, 84(5), 585-607.

Fetterman, D. (1989). Ethnography: Step by step. Newbury Park, CA: Sage.

Gracia, E., \& Musitu, G. (2003). Social isolation from communities and child maltreatment: A cross-cultural comparison. Child Abuse and Neglect, 27, 153-168.

Greenland, K., \& Brown, R. (2005). Acculturation and contact in Japanese students studying in the United Kingdom. The Journal of Social Psychology, 145(4), 373-389.

Hartman, A. (1994). Setting the theme: Many ways of knowing. In E. Sherman \& W. J. Reid (Eds.), Qualitative research in social work (pp. 459-463). New York: Columbia University Press.

Hobfoll, S. E. (1988). The ecology of stress. New York: Hemisphere Publishing.

Hobfoll, S. E. (1998). Stress, culture, and community: The psychology and philosophy of stress. New York: Plenum Press.

Hogan, P. T., \& Siu, S. (1988). Minority children and the child welfare system: An historical perspective. Social Work, 33(6), 493-498.

Korbin, J. E. (2002). Culture and child maltreatment: Cultural competence and beyond. Child Abuse and Neglect, 26, 637-644.

Korbin, J. E. (2003). Neighborhood and community connectedness in child maltreatment research. Child Abuse and Neglect, 27, 137-140.

Lincoln, Y. (1995). Emerging criteria for quality in qualitative and interpretive research. Qualitative Inquiry, 1(3), 275-289.

Lincoln, Y. S., \& Guba, E. G. (1985). Naturalistic enquiry. Newbury Park, CA: Sage. 
Maiter, S. (2003). The context of culture: Social work with South AsianCanadians. In A. Al-Krenawi \& J. Graham (Eds.), Cross-cultural social work practice with diverse ethno-racial communities in Canada (pp. 365-387). Toronto: Oxford University Press.

Maiter, S. (2004). Considering context and culture in child protection services to ethnically diverse families: An example from research with parents from the Indian sub continent (South Asians). Social Work Research and Evaluation, 5(1), 63-80.

Maiter, S., Alaggia, R., \& Trocmé, N. (2004). Perceptions of child maltreatment by parents from the Indian subcontinent: Challenging myths about culturally based abusive parenting practices. Child Maltreatment, 9(3), 309-325.

Manji, S., Maiter, S., \& Palmer, S. (2005). Community and informal support for recipients of child protective services. Child and Youth Services Review, 27(3), 291-308.

McCracken, G. (1988). The long interview. Newbury Park, CA: Sage.

Pieper, M. H. (1989). The heuristic paradigm: A unifying and comprehensive approach to social work research. Smith College Studies in Social Work, $60,8-34$.

Pine, B. A., \& Drachman, D. (2005). Effective child welfare practices with immigrant and refugee children and their families. Child Welfare, 84(5), 537-563.

Rhee, S., Chang, J., \& Youn, S. (2003). Korean American pastors' perceptions and attitudes toward child abuse. Journal of Ethnic and Cultural Diversity in Social Work, 12(1), 27-46.

Roer-Strier, D. (2001). Reducing risk for children in changing cultural contexts: Recommendations for intervention and training. Child Abuse and Neglect, 25, 231-248.

Roer-Strier, D., \& Rosenthal, M. K. (2001). Socialization in changing cultural contexts: A search for images of the "adaptive adult." Social Work, 46(3), 215-228.

Ruckdeschel, R., Earnshaw, P., \& Firrek, A. (1994). The qualitative case study and evaluation: Issues, methods, and examples. In E. Sherman \& W. J. Reid (Eds.), Qualitative research in social work (pp. 252-264). New York: Columbia University Press.
Segal, U. A., \& Mayadas, N. S. (2005). Assessment of issues facing immigrant and refugee families. Child Welfare, 84(5), 563-584.

Sherman, E., \& Reid, W. J. (1994). Introduction: Coming of age in social work-The emergence of qualitative research. In E. Sherman \& W. J. Reid (Eds.), Qualitative research in social work (pp. 1-15). New York: Columbia University Press.

Strauss, A., \& Corbin, J. (1998). Basics of qualitative research: Techniques and procedures for developing grounded theory. Thousand Oaks, CA: Sage.

Zheng, X., \& Berry, J. W. (1991). Psychological adaptation of Chinese sojourners in Canada. International Journal of Psychology, 26, 451-470.

Sarah Maiter, MSW, PhD, is assistant professor, School of Social Work, York University, Toronto, Canada. Maiter has extensive practice experience in the child welfare and is executive board member and chair of the diversity committee of the American Professional Society on the Abuse of Children. Carol A. Stalker, PhD, is professor, Faculty of Social Work, Wilfrid Laurier University, Kitchener, Ontario, Canada. Ramona Alaggia, $\mathrm{PhD}$, is associate professor, Faculty of Social Work, University of Toronto, Ontario, Canada. Correspondence regarding this article may be sent to the first author at smaiter@yorku.ca or Wilfrid Laurier University, Faculty of Social Work, 120 Duke Street W, Kitchener, ON, N2H 3W8.

Authors' note. The article has been published with the help of a grant from the Social Sciences and Humanities Research Council of Canada through the Standard Research Grants Program.

Manuscript received: November 16, 2006

Revised: February 27, 2007

Accepted: March 19, 2007

Continuing education credit based on this article can be earned online. Go to FamiliesInSociety.org to learn more. 